\title{
Mercados y Negocios (1665-7039)
}

Vol. 1, Núm. 36 (2017)

\section{Carta del editor}

En primer término, se notifica que la Revista Mercados y Negocios está en proceso de transición. Esto implica abandonar el formato impreso para convertirse en un instrumento de comunicación científica cien por ciento digital. Lograr dicha conversión conlleva una tarea compleja y el compromiso de la comunidad para familiarizarse con los medios electrónicos y adaptar el proceso de edición a estos últimos. Se espera que, con esta nueva etapa los autores disfruten tanto de una mayor inmediatez en la comunicación de sus resultados como de una mayor visibilidad que contribuya a la discusión de los mismos.

El compromiso que adquieren los autores para apoyar esta tarea implica contar con un identificador ORCID (Open Researcher and ContributorID) y registrarlo en el sistema Open Journal System al momento de abrir una cuenta como autor en la revista. ORCID es una herramienta para la normalización de la firma de los investigadores, que les permite registrar sus datos, sus trabajos y reclamar la autoría de los mismos. Se trata de un identificador compuesto por 16 dígitos y basado en la norma ISO 27729:2012.

De acuerdo con la Universidad de Deusto, los principales beneficios de ORCID para el autor son: desambiguación de nombres y correcta atribución de publicaciones; incorporación automática de publicaciones y otras actividades de investigación; simplificación de las tareas de evaluación de la actividad investigadora; integración en sistemas de gestión de la producción científica; opción de firmar con el ORCID los envíos de artículos a las revistas y se mantiene independientemente de que el investigador cambie su afiliación (Deusto, 2017). Invitamos por ello a nuestros autores a postular con su identificador ORCID asociado.

Otro compromiso de los autores hacia la revista, en su formato electrónico, es la observación cuidadosa de los lineamientos y demás requisitos para la postulación de los artículos. Muchos de los detalles requeridos al autor facilitan el maquetado y la difusión de los trabajos en la web. Lamentablemente, es recurrente el caso de autores que no conservan el sistema para referencias de forma homogénea, o que agregan formatos de edición y tipos de letra que obstruyen el trabajo de edición. Cuidar estos detalles agiliza la comunicación científica digital y permite conservar las publicaciones de los trabajos como gratuitas. 
En segundo término, presentamos el número 36. En este número, que se publica en formato tanto impreso como electrónico, dando prioridad a la versión electrónica, se incluyen siete artículos de investigación. El primer trabajo se titula "Talento humano: una contribución a la competitividad organizacional", presentado por Enore Adriana Chávez Jiménez y Antonio de Jesús Vizcaíno. El objetivo del mismo es identificar la relación entre el talento humano y la competitividad de las organizaciones. Los autores encontraron que las personas constituyen un recurso valioso dentro de la organización y la formación del talento humano es una variable determinante para lograr la competitividad de las organizaciones.

El trabajo "Emprendimiento e innovación como detonadores de negocios competitivos en el mercado de servicios" ocupa el segundo lugar y es presentado por Bitia Betsaida Rivas Aragón, María Angélica Cruz Reyes y Rebeca Meléndez Flores. En este se determina la viabilidad del negocio de servicios, al evaluar dos de las etapas de un plan de negocios. Entre los hallazgos encontrados está la viabilidad de mercado, pero no la económica-financiera.

"Determinantes y modelos para medir el desempeño de una cadena de suministro agroalimentaria: una revisión de la literatura" es el tercer artículo, cuyos autores son Ariel Gutierrez Ortiz y Zoe Tamar Infante Jiménez. El propósito de su investigación fue identificar, a través de una revisión de la literatura, los factores determinantes y modelos que se utilizan con mayor frecuencia para medir el desempeño de la cadena de suministro agroalimentaria.

Viviana Lambreton Torres y Eduardo Rivas Olmedo evidencian el impacto que generará la aplicación de la IFRS 16 en las métricas de rentabilidad ROA, ROE y en el margen de utilidad. Así como en las razones de apalancamiento financiero y liquidez para que, tanto los responsables de la información como los usuarios de la misma, tengan conocimiento de este efecto. Además, presentan los principales requerimientos que establece para que los tomadores de decisiones, tanto de las empresas privadas como de las públicas, puedan anticiparse y prepararse adecuadamente al cambio. Esto lo hacen a través del cuarto artículo "Nueva norma de arrendamiento IFRS 16 Leases y su impacto financiero y contable".

En "Liderazgo estratégico en los mandos medios de la Comisión Federal de Electricidad”, Miguel Cruz Vázquez, Miguel Ángel Lezama Torres y Beatriz Pico 
González, buscan identificar y clasificar las prácticas de liderazgo estratégico que aplican los mandos medios de la Comisión Federal de Electricidad. La metodología utilizada para la identificación y clasificación de dichas prácticas fue el diseño y la aplicación de una encuesta a 120 trabajadores activos de mandos medios ubicados en las distintas divisiones de distribución de la CFE de todo el país y la utilización del método estadístico de componentes principales.

A Jorge Antonio Rangel Magdaleno, Jesús Salvador Vivanco Florido, José Manuel Barrera Castañeda y Martha González Adame corresponde la autoría del sexto artículo, "Capital humano, relacional y estructural en la actividad innovadora de las pequeñas y medianas empresas". Este estudio empírico mide la influencia que ejercen el capital humano, relacional y estructural en la actividad innovadora de las empresas del Estado de Aguascalientes, México.

"Factores que determinan el nivel de competitividad internacional en British American Tobacco LTD” es el séptimo y último artículo. José Roberto Ramones Garza y otros analizan la manera en que afectan la innovación de producto y las estrategias de segmentación a la competitividad internacional.

Dr. José Sánchez Gutiérrez Editor

\section{REFERENCIAS}

Deusto (2017). ORCID Beneficios. Deusto: Universidad de Deusto. Link http://biblioguias.biblioteca.deusto.es/c.php?g=437729\&p=2983440 


\section{Carta del editor}

MERCADOS y Negocios 